\title{
Optical characteristics of novel bulk and nanoengineered laser host materials
}

Narasimha S. Prasad, Stacey Sova, Lisa Kelly, Talon Bevan, Bradley Arnold, et al.

Narasimha S. Prasad, Stacey Sova, Lisa Kelly, Talon Bevan, Bradley Arnold, Christopher Cooper, Fow-Sen Choa, N. B. Singh, "Optical characteristics of novel bulk and nanoengineered laser host materials," Proc. SPIE 10533, Oxide-based Materials and Devices IX, 1053320 (23 February 2018); doi: 10.1117/12.2295994

SPIE. Event: SPIE OPTO, 2018, San Francisco, California, United States 


\title{
Optical characteristics of novel bulk and nanoengineered laser host materials
}

\author{
Narasimha S. Prasad ${ }^{+}$, Stacey Sova, Lisa Kelly, Talon Bevan, Bradley Arnold, Christopher \\ Cooper, Fow-Sen Choa, and N. B. Singh \\ University of Maryland, Baltimore County, 1000 Hilltop Circle, Baltimore MD 21250 \\ ${ }^{+}$NASA Langley Research Center, Laser Remote Sensing Branch, 5 North Dryden Street, \\ Hampton, VA 23681
}

\begin{abstract}
The hexagonal apatite single crystals have been investigated for their applications as laser host materials. Czochralksi and flux growth methods have been utilized to obtain single crystals. For low temperature processing $\left(<100{ }^{\circ} \mathrm{C}\right)$, several techniques for crystal growth have been developed. The hexagonal apatite structure (space group $\mathrm{P}^{6} 3 / \mathrm{m}$ ) is characteristic of several compounds, some of which have extremely interesting and useful properties as laser hosts and bone materials. Calcium lanthanum silicate (Nd-doped) and lanthanum aluminate material systems were studied in detail. Nanoengineered calcium and lanthanum based silicates were synthesized by a solution method and their optical and morphological characteristics were compared with Czochralski grown bulk hydroxyapatite single crystals. Materials were evaluated by absorbance, fluorescence and Raman characteristics. Neodymium, iron and chromium doped crystals grown by a solution method showed weak but similar optical properties to that of Czochralski grown single crystals.
\end{abstract}

Keywords: Laser, Apatite, crystals, transition metal, dopants, optical emission, transparency

\section{INTRODUCTION}

There is a strong need to find suitable laser host materials for high damage threshold and high efficiency laser applications. The hexagonal apatites of several compounds have extremely interesting [1-5] and useful properties [2-7] to be very good laser host and bone materials. The mineral fluorapatite (FAP), which has the composition $\mathrm{Ca}_{5}\left(\mathrm{PO}_{4}\right)_{3} \mathrm{~F}$, provided the lowest thresholds and highest efficiency of many currently known Nd laser hosts. The high efficiency of this host in long pulse operation (slope and overall efficiency) has been attributed to the favorable site symmetry of the lasing ion in the apatite structure which promotes a broad absorption spectrum. The unique properties of the fluorapatite make them a natural host for Ho as well. Indeed, successful laser action has been obtained from Ho activated FAP crystals. Laser oscillation occurred at $2.07 \mu \mathrm{m}$ with a threshold of about 20 joules. Successful laser operation is attributed to the addition of transition metal $\mathrm{Cr}$ which is an effective sensitizer for Ho. The silicate oxyapatites (known as SOAP), have the general chemical formula $\mathrm{MR}_{4}\left(\mathrm{SiO}_{4}\right)_{3} \mathrm{O}$, where $\mathrm{M}$ is a divalent ion such as $\mathrm{Ca}$ or $\mathrm{Sr}$, and $\mathrm{R}$ is a trivalent rare earth, e.g., $\mathrm{La}, \mathrm{Y}$ or $\mathrm{Gd}$, have been studied extensively in the past. Since activating and sensitizing ions such as $\mathrm{Ho}, \mathrm{Er}$, and Tm have the potential to be more readily substituted for the rare-earth constituent in SOAP than for Ca in FAP, these apatite materials should provide exceptionally good hosts for laser action. In this paper, we report results of synthesis of nanoengineered calcium and lanthanum based silicates and compare their optical characteristics with Czochralski (CZ) grown bulk hydroxyapatite single crystals. Emission characteristics, such as absorbance, fluorescence, Raman and fluorescent lifetimes, and structural characteristics were determined for evaluating their suitability for rare earth doping.

\section{EXPERIMENTAL METHOD}

The experimental approach involved five major tasks:

1. Preparation of nanoengineered polycrystalline host material and doping

2. Sintering and grain growth of doped material

3. Sensitization and optimization of dopants based on spectroscopic and laser tests

4. Comparison of optical performance with single crystals

5. Determine effect of transition metal doping in place of rare earth. 
Our approach used chemical synthesis using oxides and crystallized the desired composition. Samples were prepared in rapid and efficient manner. Nanocrystals were prepared by mixing powders in stoichiometric ratio, with a $1 \%$ weight of dopant, and annealed at $500^{\circ} \mathrm{C}$ or $900^{\circ} \mathrm{C}$ followed by precipitation by either dilute nitric acid or acetone. By quenching the materials, the normal segregation of dopants occurring during single crystal growth could be minimized. This could result in more homogenized host material. The samples were then characterized by absorbance, fluorescence, Raman and scanning electron microscopy. These compounds were compared with available Czochralski grown bulk hydroxyapatite single crystals of the same composition and their efficiency as laser host materials were determined.

\subsection{EXPERIMENTAL METHODS AND RESULTS}

Calcium lanthanum silicate and lanthanum aluminate single crystals, obtained from Northrop Grumman Corporation, were grown by Czochralski method. The Czochralski grown calcium lanthanum silicate crystals came in two shapes, a rod and a slab form while the lanthanum aluminate crystal came in a rod shape but was cut as shown in Figure 1.

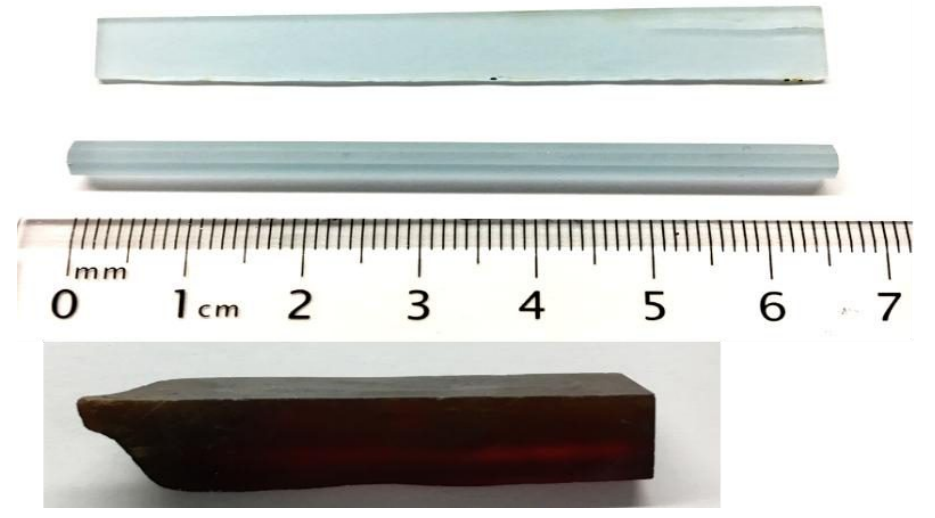

Figure 1. Calcium lanthanum silicate single crystal in rod and slab form (top) and lanthanum aluminate single crystal (bottom) grown by the Czochralski method

\subsection{Reactive solution growth method for nanocrystalline materials:}

Lanthanum oxide, aluminum oxide, neodymium(III) oxide, iron(III) chloride, chromium(III) chloride hexahydrate and calcium carbonate were received from Sigma Aldrich and were used as received. Using a solution method, $\mathrm{CaLa}_{4}\left(\mathrm{SiO}_{4}\right)_{3}$ and $\mathrm{LaAlO}_{3}$ nanocrystals were prepared by mixing stoichiometric ratios of the starting materials to yield about a 4 gram mixture. The dopant, neodymium, iron or chromium was added as a $10 \%$ stoichiometric concentration. This mixture was washed with either $10 \%$ nitric acid or acetone and the precipitate was then heated to $900^{\circ} \mathrm{C}$ at $10^{\circ} \mathrm{C} / \mathrm{min}$ and then held for 2 hours. This powder was cooled to room temperature over a span of 6 hours. This mixture was then washed again with either dilute nitric acid or acetone. The final product was then characterized as a powder. Figure 2 shows morphology of the powders obtained from each dopant.

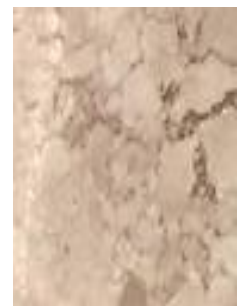

$\mathrm{Nd}$

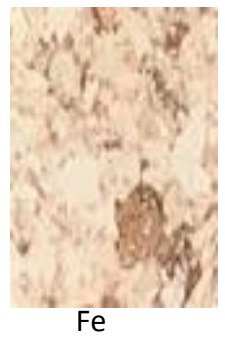

$\mathrm{Fe}$

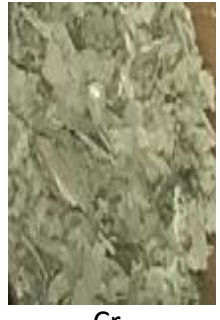

$\mathrm{Cr}$

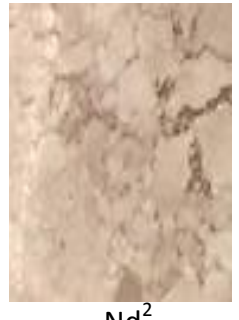

$\mathrm{Nd}^{2}$
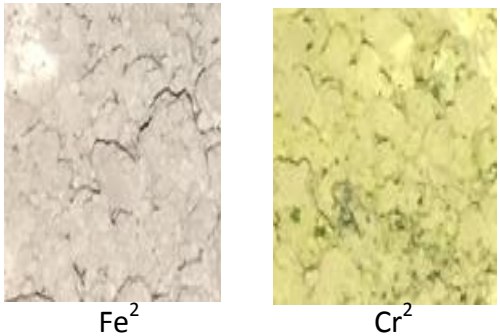

Figure 2. Morphology of powders obtained from different dopants of calcium lanthanum silicates (left) and lanthanum aluminate $\left(\mathrm{X}^{2}\right)$ on right. 
A neodymium-doped phosphosilicate hydroxyapatite crystal was formed by the solution method as well. Sodium carbonate $(0.6 \mathrm{~g})$, calcium oxide $(2.0 \mathrm{~g})$, magnesium oxide $(0.2 \mathrm{~g})$, potassium carbonate $(1.2 \mathrm{~g})$, titanium oxide $(0.1$ $\mathrm{g})$, gallium oxide $(0.4 \mathrm{~g})$ and silicon dioxide $(5.3 \mathrm{~g})$ were prepared by the same solution growth method as mentioned previously with a $10 \%$ stoichiometric ratio of neodymium chloride added. This multi-component hydroxyapatite produced a white powder with grains that showed glassy behavior, as shown in the micrograph in Figure 3 taken by NanoSEM Nova-450. Morphology shows presence of large grains and boundaries.

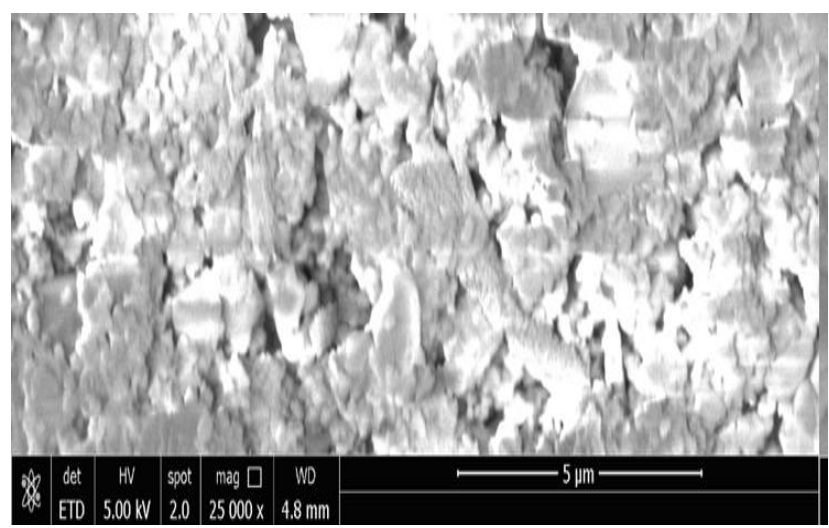

(a)

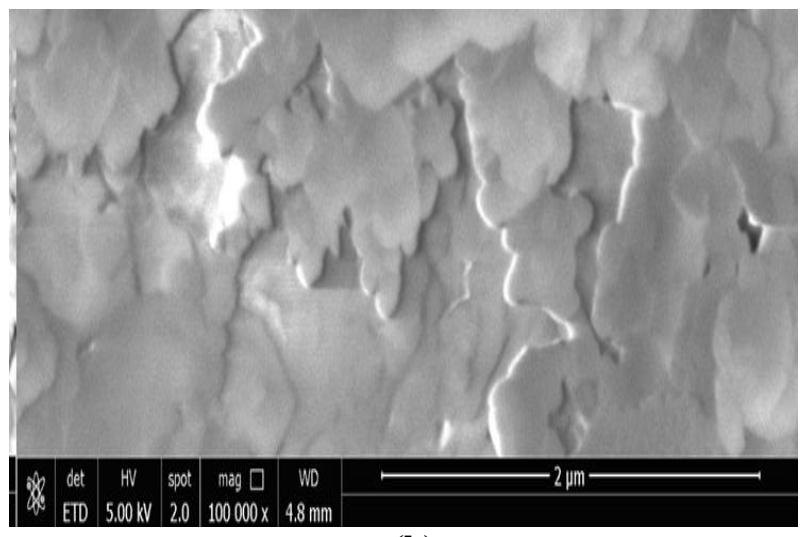

(b)

Figure 3. Morphology of Nd-doped phosphosilicate at (a) low and (b) high magnification showing large grains with boundaries.

\subsection{Optical characterization of single crystals:}

The optical properties of the neodymium-doped $(\mathrm{Nd})$ calcium lanthanum silicate and lanthanum aluminate single crystals grown by the Czochralski method were obtained and compared. The excitation and emission spectra of the crystals are shown in Figure 4. All data for the Czochralski grown calcium lanthanum silicate crystal was from the rod shape crystal. Both shapes displayed the same absorption and fluorescence properties. However, in the excitation spectrum the slab form had greater absorbance at 355 and $532 \mathrm{~nm}$, where the rod had a more distributed excitation spectrum with peak absorbance at 355, 532, 590, 750 and $800 \mathrm{~nm}$. The data for the slab form of the calcium lanthanum silicate is not shown.

The host media changed the excitation and emission spectra of these neodymium doped crystals. Again, the calcium lanthanum silicate has discrete absorbance peaks, but over a broad range of wavelengths. The maximum absorbances for the lanthanum aluminate crystal were at $750 \mathrm{~nm}$ and $800 \mathrm{~nm}$ whereas the calcium lanthanum silicate crystal's maximum absorbance was at 355 and $532 \mathrm{~nm}$. The absorbance spectra for both media are similar with peaks at the same wavelengths, but the intensities are vastly different. For the emission spectra, both media have the maximum emission at $1064 \mathrm{~nm}$, with less intense emission at 875, 910, and $1340 \mathrm{~nm}$. These peaks are characteristic of neodymium-doped substrates and these transitions have been previously determined. Fluorescence around 900 nm corresponds to an ${ }^{4} \mathrm{~F}_{3 / 2}{ }^{4} \mathrm{I}_{9 / 2}$ transition, $1064 \mathrm{~nm}$ a ${ }^{4} \mathrm{~F}_{3 / 2}{ }^{4} \mathrm{I}_{11 / 2}$ and at $1340 \mathrm{~nm}$ the fluorescence corresponds to a $\mathrm{F}_{3 / 2}{ }^{4} \mathrm{I}_{13 / 2}$ transition. The emission spectra of lanthanum aluminate had broader emission peaks as compared to the discrete emission peaks for the silicate host material. At $1064 \mathrm{~nm}$, the full-width half-maximum for the aluminate crystal was $34 \mathrm{~nm}$ and for the silicate it was only $5 \mathrm{~nm}$. This may be due to the difference in the crystal's structure and width rather than the material itself. Both materials have signature signals at $1200 \mathrm{~nm}$, which move based on the excitation wavelength with a shift of $4167 \mathrm{~cm}^{-1}$ or higher which changed based on the excitation wavelength. This signal is not due to a Raman shift because of the change in shift based on excitation, it may rather be due to different color centers being excited. 

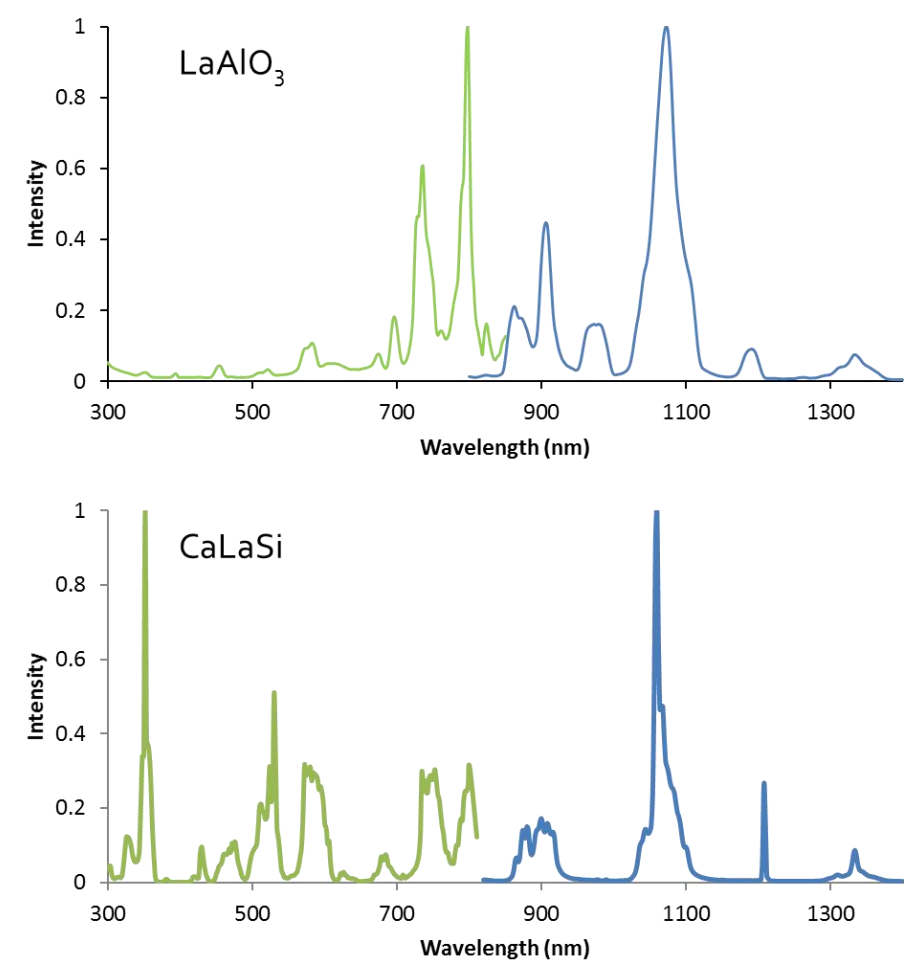

Figure 4. Excitation and emission spectra of neodymium-doped lanthanum aluminate (top) and calcium lanthanum silicate (bottom). Excitation at $800 \mathrm{~nm}$, Emission set at $1064 \mathrm{~nm}$.

\subsection{Optical characterization and comparison of solution growth nanocrystals:}

Solution growth samples were prepared with a stoichiometric amount of host media (lanthanum aluminate and calcium lanthanum silicate) and dopants (neodymium, iron and chromium) and the optical properties were taken from the resultant powder or crystals that formed. The absorbance and fluorescence of the filtrate and solid were recorded for every sample. The absorbance for the filtrate of neodymium doped calcium lanthanum silicate and lanthanum aluminate were identical, as shown in Figure 5, which indicated the media did not influence the absorbance characteristics. The absorbance maxima in solution matched those of the solid Czochralski grown crystals as well.

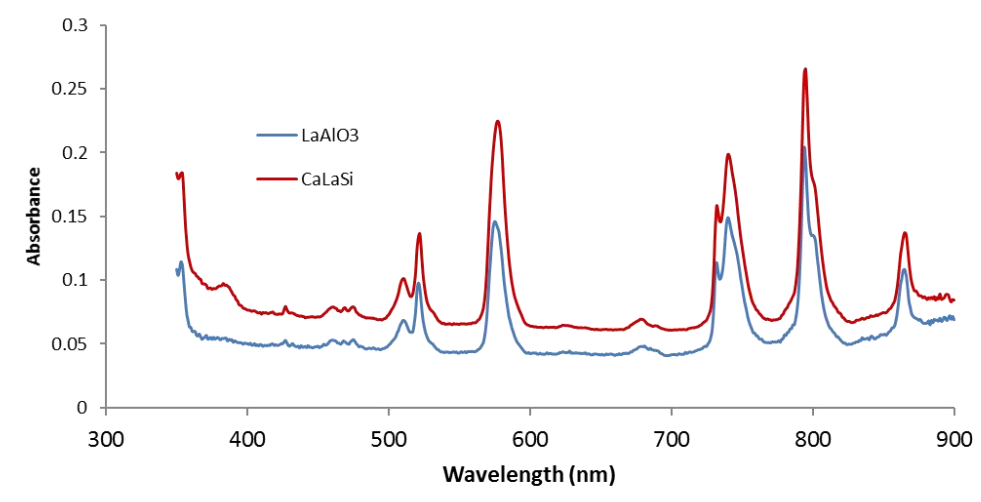

Figure 5. Absorbance spectra of neodymium-doped calcium lanthanum silicate (red) and lanthanum aluminate (blue) filtrate in $10 \%$ nitric acid solution. 


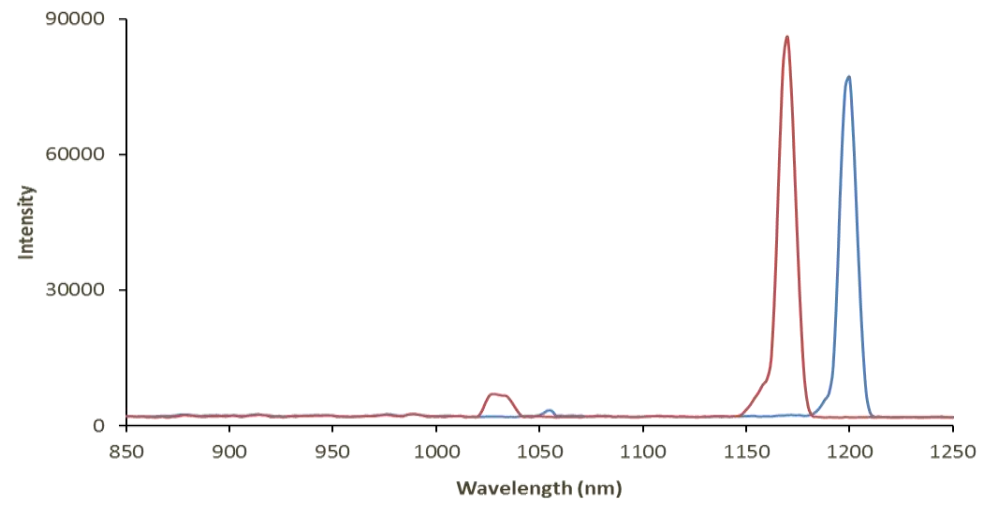

Figure 6. Emission spectra of neodymium-doped calcium lanthanum silicate solid. Excited at $780 \mathrm{~nm}$ (red) and 800 nm (blue).

Although the Nd-absorbance characteristics were the same, the fluorescence spectra were different. The filtrates of chromium and iron doped laser host media did not have discrete absorbance maximum. Iron-doped materials had no characteristic absorbance peaks, but rather a broad absorbance that increased exponentially below $450 \mathrm{~nm}$. The chromium filtrate in acetone had absorption maxima at 430 and $650 \mathrm{~nm}$. There were signature peaks in all the fluorescence spectra around 1050 and $1200 \mathrm{~nm}$, which was determined based on shifts in emission coinciding with shifts in excitation wavelength. This corresponds to a Raman shift of $3030 \mathrm{~cm}^{-1}$ and $4167 \mathrm{~cm}^{-1}$, the latter occurring

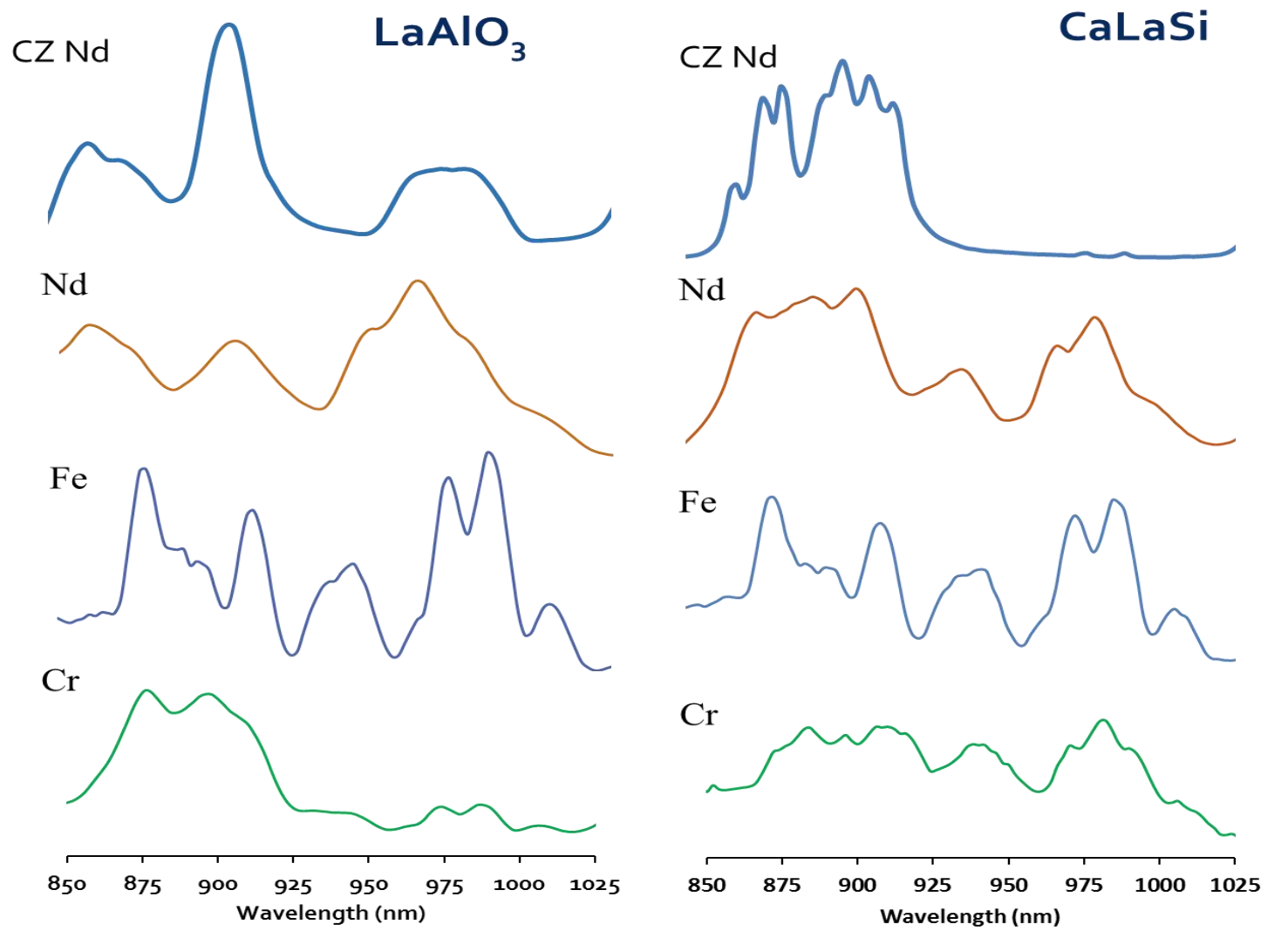

Figure 7. Fluorescence spectra of $\mathrm{Nd}, \mathrm{Fe}$, or $\mathrm{Cr}$-doped lanthanum aluminate and calcium lanthanum silicate grown by the Czochralski method (CZ top) and solution growth. Excitation was at $800 \mathrm{~nm}$. 
in the Czochralski grown crystals. This hindered detecting any fluorescence between these wavelengths due to the intensity. However, due to these changes in the magnitude of the shift based on excitation wavelength, these are not Raman bands. These were likely due to different color center excitation within the crystal. The maximum emission for the Czochralski crystals was $1064 \mathrm{~nm}$ for each, but this cannot be determined for the crystals generated by the solution growth method. Therefore, all the fluorescence data was collected between 800 and $1025 \mathrm{~nm}$. In order to compare the emission spectra for the different doped materials, the intensities were normalized.

The comparison of emission spectra for all the dopants of calcium lanthanum silicate and lanthanum aluminate solids are displayed in Figure 7. The Nd-doped lanthanum aluminate single crystal has 3 distinct fluorescence maxima at 860, 900 and $975 \mathrm{~nm}$, typical of the ${ }^{4} \mathrm{~F}_{3 / 2}-{ }^{4} \mathrm{I}_{9 / 2}$ transition. The solution growth crystal doped with $\mathrm{Nd}$ showed a similar fluorescence pattern at the same wavelengths, although the most intense peak is at $975 \mathrm{~nm}$ instead of $900 \mathrm{~nm}$. Cr doped solution growth crystal also showed similar transitions to the CZ grown crystal, but with a broad fluorescence from 850-925 nm and weak fluorescence at $975 \mathrm{~nm}$. Iron doped solution growth method did not display any similar transitions to that of the $\mathrm{CZ}$ grown crystal.

The Nd-doped calcium lanthanum silicate Czochralski grown crystal had at least 2 distinct peaks in the range of $850-925 \mathrm{~nm}$. The Nd-doped powder grown by the solution method most closely resembles the emission profile of the single crystal with broad emission from $850-925 \mathrm{~nm}$. There are two extra emission peaks at 930 and 980 in this nanoengineered form that didn't appear in the single crystal. The emission for iron and chromium doped calcium lanthanum silicate solids also contain these extra fluorescent peaks at 930 and $980 \mathrm{~nm}$, however don't show any resemblance to the characteristic fluorescence pattern on the CZ grown crystal.

Both the Nd-doped single crystals had the highest emission intensity over a magnitude higher than the solids grown by solution method. The relative intensity of the solids was calculated by taking the highest intensity peak from each doped material and taking a ratio compared to the Czochralski grown crystal. The relative intensities are displayed in Table 1. The lanthanum aluminate solution growth crystals had the most intense fluorescence from doping with chromium, followed by neodymium and then iron. Iron had only $5 \%$ of the intensity of the Czochralski grown crystal. For the calcium lanthanum silicate, the only fluorescent material from the solution growth method was with

Table 1. Relative fluorescent intensities of $\mathrm{Nd}, \mathrm{Fe}, \mathrm{Cr}$ doped lanthanum aluminate and calcium lanthanum

\begin{tabular}{|c|c|c|}
\hline Dopants & LaAlO $_{3}$ & CaLaSi \\
\hline CZ grown crystal Nd & 1 & 1 \\
\hline $\mathrm{Nd}$ & 0.793 & 0.578 \\
\hline $\mathrm{Fe}$ & 0.051 & 0.0309 \\
\hline $\mathrm{Cr}$ & 0.832 & 0.0265 \\
\hline
\end{tabular}
solution is presented sin acetone, needed to be used for preparing the phosphosilicate solid. Overall, the solution growth method for Nd-doped lanthanum aluminate, calcium lanthanum silicate and phosphosilicate host media produced crystals with properties that closely resemble the Czochralski grown single crystals.

Figure 8. Excitation and emission spectra of neodymium-doped phosphosilicate in $10 \%$ nitric acid solution. Excitation at $800 \mathrm{~nm}$, Emission was set at $1064 \mathrm{~nm}$. doping from neodymium. Iron and chromium were basically non-fluorescent having only $2-3 \%$ of the fluorescent intensity as the Czochralski grown crystal. The filtrate of each doped solution was tested for fluorescent properties as well, but the numbers were negligible compared to the solids, except for the Nd-doped phosphosilicate. There was no fluorescence in the solid material, but there were signature absorbance and fluorescence transitions in the $10 \%$ nitric acid filtrate solutions. The solution had fluorescence maxima at $850 \mathrm{~nm}$ and $1050 \mathrm{~nm}$ and "Raman" peak at $1200 \mathrm{~nm}$, similar to that of the Nd-doped Czochralksi single crystals. The excitation and emission of the phosphosiliciate in

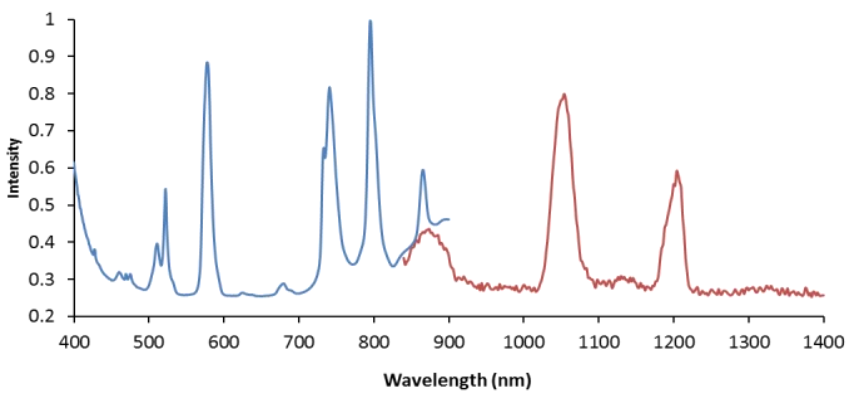




\section{SUMMARY}

The solution growth method at lower temperatures for doped calcium lanthanum silicate, lanthanum aluminate and phosphosilicate showed favorable properties that have the potential to be used as laser host materials with fluorescent properties above $900 \mathrm{~nm}$. Iron-doped material did not produce fluorescent properties. However, chromium can be used as an alternative to neodymium as a transition metal to produce lasing in lanthanum aluminate host media. The properties of these solution grown crystals can be optimized to produce more discrete and intense fluorescence with alterations in filtrate solutions, heating time and temperature gradients. Following optimizing the growth conditions, systematic testing of different transition metals to achieve desired fluorescence properties can also be accomplished. The solution growth method for Nd-doped lanthanum aluminate, calcium lanthanum silicate and phosphosilicate host media produced crystals with comparable properties to that of the Czochralski grown single crystals. These preliminary results show the low temperature solution growth method is promising for producing long wavelength laser host materials.

\section{ACKNOWLEDGEMENT}

One of the authors Stacey thanks to NASA Langley Research Center, Hampton, VA for the summer intern support. We also thank several undergraduate students for their help during the tenure of this work.

\section{REFERENCES}

1. K. B. Steinbruegge, T. Henningsen, R. H. Hopkins, R. Mazelsky, N. T. Melamed, E. P. Riedel and G. W. Roland, "Laser properties of $\mathrm{Nd}(+3)$ and $\mathrm{Ho}(+3)$ doped crystals with the apatite structure". Appl Opt. 11(5): 9991012, 1972.

2. B. Rami Reddy, Kenneth Schepler, Elizabeth Moore, John Hoelscher, Shiva Vangala, Bruce Claflin,, Narsingh B. Singh, Jonathan Evans, Patrick Berry, "Surface characterization studies of orientation patterned ZnSe doped with $\mathrm{Cr}_{2}^{+}$," SPIE Proceeding: Nonlinear Frequency Generation and Conversion: Materials, Devices, and Applications XIV, edited by Konstantin L. Vodopyanov Volume 9347: XIV, 93471-11, April 2015

3. D. Welford and P. F. Moulton, "Room-temperature operation of a Co:MgFz laser," Opt. Lett., vol. 13, pp. 957977, 1978.

4. L. D. DeLoach, R. H. Page, G. D. Wilke, S. A. Payne, and W. F. Kmpke, "Spectral properties of transition metaldoped zinc chalcogenide crystals for tunable IR radiation," presented at the Topical Meet. on Advanced SolidState Lasers, Memphis, TN, Feb. 1995.

5.L. D. DeLoach, R. H. Page, G. D. Wilke, S. A. Payne, and W. F. Kmpke, "Transition metal-doped zinc chalcogenide: Spectroscopy and laser demonstration of new gain media", IEEE Quantum Electronics 32(6) 885$895,1996$.

6. H. A. Weakliem, "Optical spectra of $\mathrm{Ni}^{2+}, \mathrm{CO}^{2+}$, and $\mathrm{Cu}^{2+}$ in tetrahedral sites in crystals," J. Chem. Phys., vol. 36, pp. 2117-2140, 1962.

7.H. Uchiike, "Review of flat panel displays: Electroluminescence displays, liquid crystal displays, plasma displays, etc.," in Electrolumin.Proc. Fourth Int. Workshop, S. Shionoya and H. Kobayashi, Eds. Berlin: Springer-Verlag, 1,238-245., (1989) 